\title{
Harassment Patterns and Risk Profile in Spanish Trans Persons
}

\author{
José Devís-Devís, Sofía Pereira-García, Alexandra Valencia-Peris, Jorge \\ Fuentes-Miguel, Elena López-Cañada \& Víctor Pérez-Samaniego
}

To cite this article: José Devís-Devís, Sofía Pereira-García, Alexandra Valencia-Peris, Jorge Fuentes-Miguel, Elena López-Cañada \& Víctor Pérez-Samaniego (2017) Harassment Patterns and Risk Profile in Spanish Trans Persons, Journal of Homosexuality, 64:2, 239-255, DOI:

10.1080/00918369.2016.1179027

To link to this article: http://dx.doi.org/10.1080/00918369.2016.1179027

Accepted author version posted online: 19

Apr 2016.

Published online: 19 Apr 2016.

Submit your article to this journal $\pi$

LII Article views: 161

Q View related articles $\sqsubset$

View Crossmark data ¿

4 Citing articles: 1 View citing articles 준 


\title{
Harassment Patterns and Risk Profile in Spanish Trans Persons
}

José Devís-Devís, PhDa , Sofía Pereira-García, MSca , Alexandra Valencia-Peris, $\mathrm{PhD}^{\mathrm{b}}$, Jorge Fuentes-Miguel, MPhil ${ }^{b}$, Elena López-Cañada, MSc ${ }^{a}$, and Víctor PérezSamaniego, $\mathrm{PhD}^{\mathrm{a}}$

\begin{abstract}
aDepartamento de Educación Física y Deportiva, Facultad de Ciencias de la Actividad Física y el Deporte, Universitat de València, Valencia, Spain; 'bepartamento de Didáctica de la Expresión M. P. y Corporal, Facultad de Magisterio, Universitat de València, Valencia, Spain
\end{abstract}

\begin{abstract}
This article describes the harassment patterns and the risk profile in trans people living in Spain. A sample of 212 trans persons, aged 10-62, participated in this cross-sectional study. Results showed a high percentage of harassment (59.9\%) and frequency of daily harassment (12.6\%), especially verbal attacks (59\%) that occurred in public spaces (49.1\%) and within educational contexts $(46.2 \%)$. Harassment is more prevalent in trans women than men. Those who disclose their gender identities at a younger age experience higher percentages and frequency of harassment than those who disclose at an older age. They also suffer more harassment of different types. The risk profile of harassment indicates that older trans women are more likely to suffer harassment than younger ones, and the risk decreases each year they delay their gender identity disclosure. The elimination of transphobic attitudes and the promotion of gender justice should be priority strategies in Spain.
\end{abstract}

\section{KEYWORDS}

Bullying; harassment; transgender; transphobia; transsexuals

Harassment is a widespread phenomenon in Western societies (Juvonen \& Graham, 2001; Monks et al., 2009; Pörhölä \& Kinney, 2010). It is a harmful action or actions based on a power imbalance of different kinds between the aggressor and the victim (Holmes \& Holmes-Lonergan, 2004). Vulnerable groups are more prone to suffer harassment because they lack the necessary resources to deal with difficult situations. Particularly, vulnerability of trans people (persons whose gender do not conform to the biological sex assigned at birth) is increased by social stigmatization, as well as a weak institutional and legal support. For instance, discrimination and harassment against trans people has not been yet addressed by the enactment of certain Spanish laws about sex rectification and sex equality promotion (see Ley, 2007; Ley Orgánica, 2007). Moreover, the public display of trans identities also produces transphobic attitudes because cisgender identities (non-trans) are 
challenged, gender hierarchies are threatened, and cisgender people lose their gendered privileges existing within sociocultural contexts in which a binary sex/gender system is prevailing (Nagoshi et al., 2008; Witten \& Eyler, 1999). Some authors consider harassment against trans people a structural violence or systemic oppression that punishes whoever transgresses gender social rules (Kidd \& Witten, 2010; Lombardi, Wilchins, Priesing, \& Malouf, 2002; Puche, Moreno, \& Pichardo, 2013). Others emphasize the consequences of harassment on the health of trans persons (suicide, drug use, alcohol consumption, anxiety, or depression) as well as the effects harassment has on their future social development (e.g., school dropout, choice of spaces or types of leisure activities) (Doan, 2010; Grant et al., 2011; Haas et al., 2010; Kosciw, Greytak, Bartkiewicz, Boesen, \& Palmer, 2012).

Several empirical studies highlight prevalence data on the harassment experienced by trans people. For instance, Lombardi et al. (2002) found, in a survey study, a harassment prevalence of $59.6 \%$ in the United States between 1996 and 1997. Xavier and Simmons (2000) showed that 43\% of 252 trans residents in the District of Columbia (Washington, DC) suffered some kind of violence, $75 \%$ of them for transphobic or homophobic reasons. A recent European study with 6,579 trans participants from 28 European Union countries revealed a harassment prevalence of 58\% (FRA, 2014). Moreover, according to Factor and Rothblum (2007), trans people are subject to a higher percentage of harassment or discrimination than cisgender people (non-trans).

Certain studies focus on the different types of harassment according to social categories such as age, ethnic group, socioeconomic status, and gender identity that trans persons are victims of. Some researchers have indicated that harassment is more frequent in trans women than trans men (Cano Oncala et al., 2004; Factor \& Rothblum, 2007). Others have pointed out that it depends on the context in which harassment occurs and the age and ethnicity of the victims. For instance, more trans men than women suffer harassment in schools and other educational settings (Grant et al., 2011), the youngest have a higher probability of suffering different kinds of violence than the oldest (Cano Oncala et al., 2004; Lombardi et al., 2002), and Black people receive more attacks in certain contexts than other ethnicities (Grant et al., 2011). In addition, trans people with high economic levels have a significantly lower probability of experiencing some kind of violence (Lombardi et al., 2002).

Regarding the contexts of harassment, the Report of the National Transgender Discrimination Survey provides relevant results. Based on data from 6,456 participants, this report indicates that $78 \%$ of North American students who disclose their gender identities during primary and secondary education suffer some kind of harassment, and, in particular, $35 \%$ of them suffer physical harassment (Grant et al., 2011). The fifth National School 
Climate Survey of North America points out that $87 \%$ of trans students (aged 14 to 20) suffered verbal harassment due to their gender identity or expression, and $53 \%$ of them were physically attacked for the same reason (Greytak, Kosciw \& Díaz, 2009). In public spaces, such as parks, streets, bus stops, and other public areas, research reports $55.5 \%$ of verbal harassment, especially insults and negative comments in the streets (Lombardi et al., 2002). Within a family setting, $57 \%$ of American trans people are rejected by their relatives, and $19 \%$ of them are victims of domestic violence (Grant et al., 2011). Additionally, $66 \%$ of them are physically harassed within their own families (Kenagy \& Bostwick, 2005). As the inclusion of trans persons in the work environment grows, recent research reports that $50 \%$ of trans men and women surveyed at their jobs suffer different kinds of harassment, and 7\% of them are victims of physical aggressions (Grant et al., 2011).

In other contexts such as the health system, sport facilities, and prisons' premises, harassment is documented to a lesser extent. Available research has indicated that $28 \%$ of trans people in the United States suffer harassment in the health system (Grant et al., 2011). In penitentiaries, the Silvia Rivera Law Project Organization (2007) evidenced a higher vulnerability of transsexual women, although all interviewees denounced some kind of verbal, emotional, physical, and sexual harassment. In a study carried out in Australia, 25\% of trans participants admitted to receiving verbal harassment within sport facilities (Symons, Sbaraglia, Hillier, \& Mitchell, 2010). In fact, verbal is the type of harassment that most of the recent research has focused on. This is the sort of harassment more frequently reported in educational, health, work, and family contexts (Grant et al., 2011; Greytak et al., 2009; Grossman \& D’Augelli, 2007; Lombardi et al., 2002; Reback, Simon, Bemis, \& Gatson, 2001; Symons et al., 2010).

According to this review, although internationally a great interest in harassment experienced by trans people is observed, there is still a dearth of research in many countries. In the case of Spain, although 2014 police records show that $39.9 \%$ of all hate crime is sexuality/sexual identity related (Ministerio del Interior, 2015), the specific characteristics of harassment suffered by trans persons are still unknown.

\section{The current study}

To the best of our knowledge, this study is the first empirical approach on harassment experienced by trans people in Spain. Moreover, this is the first study to undertake a wide variety of types of harassment within different contexts, as well as to consider a sensitive variable in the study of harassment among trans people, such as the age of self-defined gender disclosure (ASEGDI). Particularly, the purpose of this cross-sectional study is twofold. First, it describes the patterns of harassment experienced by trans people: its 
prevalence, frequency, types (physical, verbal, gestural, and with material damage) and contexts (public, educational, family, work, health, sport, religious, and penitentiary) where harassment happens, according to sociodemographic variables of interest (self-defined gender identities, chronological age, and the ASEGDI). Second, it describes the risk profile of harassment in trans people based on the probability to experience harassment by types, contexts, and sociodemographic variables.

\section{Methodology}

\section{Participants}

A sample of 212 trans persons, aged 10 to $62(M=30.6, S D=10.7)$, from different regions of Spain participated in this study during the years 2012 and 2013; 44.1\% defined themselves as a trans woman or girl, and $51.1 \%$ as a trans man or boy. Also, $4.7 \%$ of this sample defined themselves in a different category.

The process of gathering a sample was influenced by the fact that public institutions and private associations do not register trans people in Spain, and trans persons do not leave a record of their transition process. Therefore, the research team used a sampling procedure formed by volunteers who were given no economic incentive for participation. The research team contacted Spanish lesbian, gay, bisexual, and transsexual (LGBT) associations to recruit voluntary members and then used a snowball strategy to ask participants to facilitate contact with other trans persons or groups who might voluntarily participate in the study. This strategy has been used in other studies with hidden or low visibility groups such as sex workers, drug consumers, or trans people (e.g., Grossman \& D’Augelli, 2007; Stotzer, 2009; Xavier \& Simmons, 2000). In our case, this granted us access to a number of trans persons who attended various Gender Identity Units, care programs for trans people, and participants in different conferences and meetings about this issue, as well as other persons individually. Some people, such as health professionals or other participants, facilitated the access to participants not linked to any LGBT associations or health system.

\section{Measures and procedure}

A survey to obtain information about different psychosocial issues related to trans people's experiences in different moments and contexts of their daily life was elaborated. This study uses only the data from perceived harassment items.

In contrast to other surveys based on data collected by telephone, e-mail, or other electronic media, in order to achieve reliable and valid data in this 
study the survey was self-administered to individuals or small groups $(n \leq 4)$ monitored by at least one member of the research team. Questions were informed from harassment literature and revised several times to facilitate participants' understanding. To refine the questionnaire, to avoid misunderstandings, and, of special importance, to agree on possible answers to gender identity of participants (see below), a pilot test with 12 trans persons from a LGBT association was performed. A diary was kept during the entire elaboration process to improve the survey and its application. Questions of varying structures (closed, semi-closed-ended, and open questions) were designed to satisfy the purposes of the study. Examples of these are (a) Closed: "Have you ever been harassed?"; (b) Semi-closed-ended: "Which of the following expressions do you use to refer to your actual gender identity? (1) woman; (2) man; (3) other-specify)"; and (c) Open: "How old were you when you first disclosed your new gender identity?"

Information on the specific meaning of the kinds of harassment inquired (physic, verbal, gestural, or with material damage) was included in the written survey and also was clarified by members of the research team when needed. At the end of the survey, some space was provided to add any extra information participants deemed relevant. Additionally, a survey protocol was established with information about its administration and application instructions for the team members in charge of this task. During the survey procedure, participants were encouraged to pose questions to resolve any doubts they might have, thus improving its understanding. They fulfilled the survey in 35 minutes on average.

Materials and procedures were approved by the Ethics Committee of the Universitat de València to guarantee ethical principles in social research with human beings. The survey respected the self-determination of trans people gender identities, and no personal data were requested. Informed consent forms authorizing the research team to publish the data of this study were signed by adult participants or by their parent or guardian if under 18 years of age. The surveys and informed consent forms were kept separately, and the data were entered in a database for its subsequent statistical usage.

\section{Variables and data analysis}

Study variables (or dependent variables) in this study were (a) harassment (experienced or not); (b) frequency of harassment (every day, once a week, several times a month, occasionally); (c) types of harassment (physical, verbal, gestural, or material damage); and (d) harassment contexts (work, educational, health, religious, penitentiary, sport, family, and public areas). Sociodemographic variables (or independent variables) were (e) self-defined gender; (f) age; and (g) ASEGDI. 
Data analysis used the IBM SPSS 22.0 statistical program. Variables were encoded, and data were typed into the program. Afterwards, some variables were recoded to facilitate the analysis and data comparison. In particular, age, harassment frequency, and the ASEGDI were subsequently regrouped to avoid decrease of subgroup size and to facilitate comparisons.

The statistical analysis consisted in the calculation of frequencies and percentages, and the findings were presented in figures and tables. Chisquare tests of independence were carried out to determine the existence of significant differences $(p<0.05)$ among the variables. The corrected standardized residuals were calculated to establish in which categories significant differences (corrected standardized residuals \pm 1.96 ) emerged. Binomial logistic regression was used to define the probability of experiencing harassment by types, contexts, and sociodemographic variables. The odds ratios were also determined, using 95\% confidence intervals (CI).

\section{Results}

\section{Harassment prevalence and frequency}

The results indicate that $59.9 \%$ of the participants have experienced some kind of harassment at some point in their lives. Moreover, $12.6 \%$ of them suffered harassment daily, $12.1 \%$ once a week, and $35.2 \%$ occasionally.

Harassment variability and its frequency by sociodemographic variables are observed in Table 1. Chi-square analysis showed significant differences in perceived harassment according to gender $\left(\chi_{(1)}^{2}=3.991 ; p<0.05 ; V=0.141\right)$ and the ASEGDI $\left(\chi_{(2)}^{2}=6.519 ; p<0.05 ; V=0.177\right)$. The study of corrected standardized residuals revealed differences in the following categories: female and male and the ASEGDI ( $\leq 16$ and $17-24$ years of age). That is, harassment

Table 1. Percentage of harassment and frequency of harassment by sociodemographic variables.

\begin{tabular}{|c|c|c|c|c|c|c|c|c|}
\hline & & & \multicolumn{6}{|c|}{ Frequency of Harassment } \\
\hline & \multicolumn{2}{|c|}{ Harassment } & \multicolumn{2}{|c|}{ Every day } & \multicolumn{2}{|c|}{ Once a week } & \multicolumn{2}{|c|}{ Occasionally } \\
\hline & $\mathrm{n}$ & $\%$ & $n$ & $\%$ & $\mathrm{n}$ & $\%$ & $\mathrm{n}$ & $\%$ \\
\hline \multicolumn{9}{|l|}{ Gender Identity } \\
\hline$\overline{\text { Trans woman }}$ & 62 & 66.7 & 12 & 19.0 & 13 & 20.6 & 38 & 60.3 \\
\hline Trans man & 57 & 52.0 & 10 & 20.0 & 10 & 20.0 & 30 & 60.0 \\
\hline \multicolumn{9}{|l|}{ Age } \\
\hline$\overline{\leq 20}$ years old & 24 & 61.5 & 4 & 19.0 & 6 & 28.6 & 11 & 52.4 \\
\hline 21-39 years old & 71 & 57.3 & 16 & 23.5 & 13 & 19.1 & 39 & 57.4 \\
\hline$\geq 40$ years old & 29 & 64.4 & 3 & 10.0 & 4 & 13.3 & 23 & 76.7 \\
\hline \multicolumn{9}{|l|}{ ASEGDI } \\
\hline$\overline{\leq 16}$ years old & 51 & 70.8 & 15 & 32.6 & 10 & 21.7 & 21 & 45.7 \\
\hline $17-24$ years old & 34 & 50.0 & 3 & 8.8 & 8 & 23. & 23 & 67.6 \\
\hline$\geq 25$ years old & 39 & 57.4 & 5 & 12.8 & 6 & 15.4 & 28 & 71.8 \\
\hline
\end{tabular}

The groups where standardized residual show \pm 1.96 are marked in bold lettering.

ASEGDI: Age of self-defined gender disclosure. 
was experienced more often by trans women (66.7\%) than trans men (52.8\%) and also more frequently by trans people who disclosed their gender identities at a younger age (70.8\%) than by those who disclosed their identities between $17-24$ years of age (50\%).

Significant differences are observed in the frequency of harassment, according to the ASEGDI $\left(\chi_{(4)}^{2}=10.468 ; p<0.05 ; V=0.210\right)$. Specifically, the study of corrected standardized residuals found differences only in the category of those who disclosed their gender at $\leq 16$ years of age. Therefore, people who disclosed their gender identities at a younger age suffered harassment occasionally (45.7\%) as opposed to on a daily basis (32.6\%).

\section{Types of harassment}

The types of harassment that trans people reported are seen in Figure 1. Verbal harassment was the type experienced the most (59\%), followed by gestural (47\%), physical (28\%), and harassment that involved material damages (19\%).

The different harassment types according to the demographic variables from our study are shown in Table 2. Chi-square analysis revealed significant differences in harassment types according to gender identity and the ASEGDI. Particularly, differences derived from the study of corrected standardized residuals indicated that physical harassment $\left(\chi_{(1)}^{2}=4.325 ; p<0.05 ; V=0.147\right)$ and verbal harassment $\left(\chi_{(1)}^{2}=3.878 ; p<0.05 ; V=0.139\right)$ were suffered by more trans women $(33.3 \%$ and $65.6 \%)$ than trans men $(20.4 \%$ and $51.9 \%)$. Moreover, the different sorts of harassment (physical: $\chi^{2}{ }_{(2)}=12.933 ; p<0.05 ; V=0.249$; verbal: $\chi_{(2)}^{2}=7.494 ; p<0.05 ; V=0.190$; gestural: $\chi_{(2)}^{2}=6.624 ; p<0.05 ; V=0,178$; material damage: $\left.\chi_{(2)}^{2}=6.883 ; p<0.05 ; V=0.182\right)$ were experienced by more trans people who disclosed their gender identities at an early age ( $\leq 16$ years old) than at an older age (17-24 years old and $\geq 25$ ), such as is indicated in Table 2.

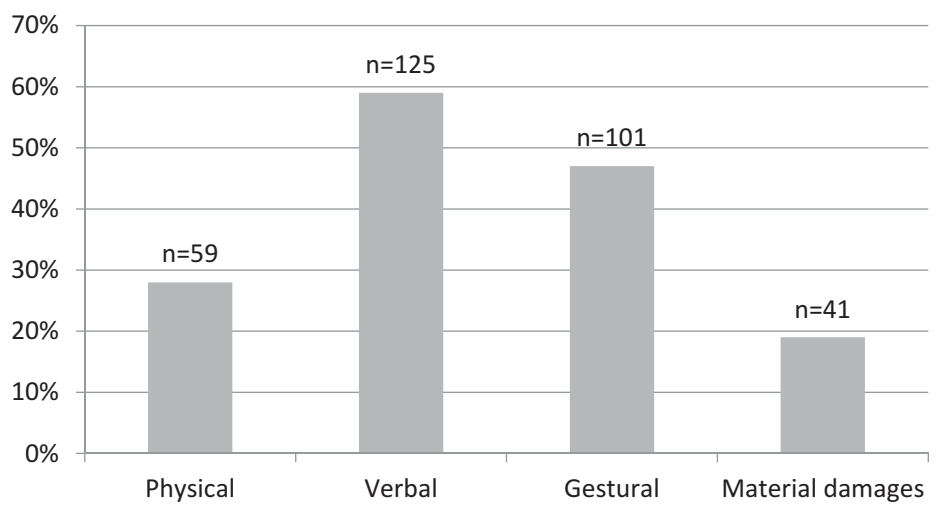

Figure 1. Percentage of types of harassment. 
Table 2. Types of harassment according to sociodemographic variables.

\begin{tabular}{|c|c|c|c|c|c|c|c|c|}
\hline & \multicolumn{2}{|c|}{ Physical } & \multicolumn{2}{|c|}{ Verbal } & \multicolumn{2}{|c|}{ Gestural } & \multicolumn{2}{|c|}{ Material Damage } \\
\hline & $\mathrm{n}$ & $\%$ & $\mathrm{n}$ & $\%$ & $\mathrm{n}$ & $\%$ & $\mathrm{n}$ & $\%$ \\
\hline \multicolumn{9}{|l|}{ Gender Identity } \\
\hline$\overline{\text { Trans woman }}$ & 31 & 33.3 & 61 & 65.6 & 49 & 52.7 & 20 & 21.5 \\
\hline Trans man & 22 & 20.4 & 56 & 51.9 & 44 & 40.7 & 17 & 15.7 \\
\hline \multicolumn{9}{|l|}{ Age } \\
\hline$\overline{\leq 20}$ years old & 11 & 28.2 & 24 & 61.5 & 16 & 41.0 & 6 & 15.4 \\
\hline $21-39$ years old & 36 & 29.0 & 69 & 55.6 & 60 & 48.4 & 28 & 22.6 \\
\hline$\geq 40$ years old & 10 & 22.2 & 29 & 64.4 & 23 & 51.1 & 6 & 13.3 \\
\hline \multicolumn{9}{|l|}{ ASEGDI } \\
\hline$\overline{\leq 16}$ years od & 31 & 43.1 & 51 & 70.8 & 42 & 58.3 & 20 & 27.8 \\
\hline $17-24$ years old & 12 & 17.0 & 33 & 48.5 & 25 & 36.8 & 13 & 19.0 \\
\hline$\geq 25$ years old & 15 & 22.1 & 38 & 55.9 & 31 & 45.6 & 7 & 10.3 \\
\hline
\end{tabular}

The groups where standardized residual show \pm 1.96 are marked in bold lettering.

ASEGDI: Age of self-defined gender disclosure.

\section{Contexts of harassment}

Trans people experienced harassment in the contexts or areas of social life as indicated in Figure 2. Public space was the context where more trans people experienced harassment (49.1\%), closely followed by the educational context (46.2\%). The third context where trans people suffered more harassment was in the family setting (31.1\%), followed by health system (24.1\%) and sport (18.9\%) contexts. Religious (11.8\%) and penitentiary (3.8\%) contexts showed the lowest percentage of trans people who suffered harassment. It is also important to highlight that $8.5 \%(n=18)$ of trans people suffered harassment in only one context, $20.8 \%(n=44)$ in two or more contexts, and $30.7 \%$ $(n=65)$ suffered it in four or more contexts.

The variability of harassment contexts according to sociodemographic variables can be seen in Table 3. Chi-square analysis showed significant differences by gender in public spaces $\left(\chi_{(1)}^{2}=4.611 ; p<0.05 ; V=0.151\right)$,

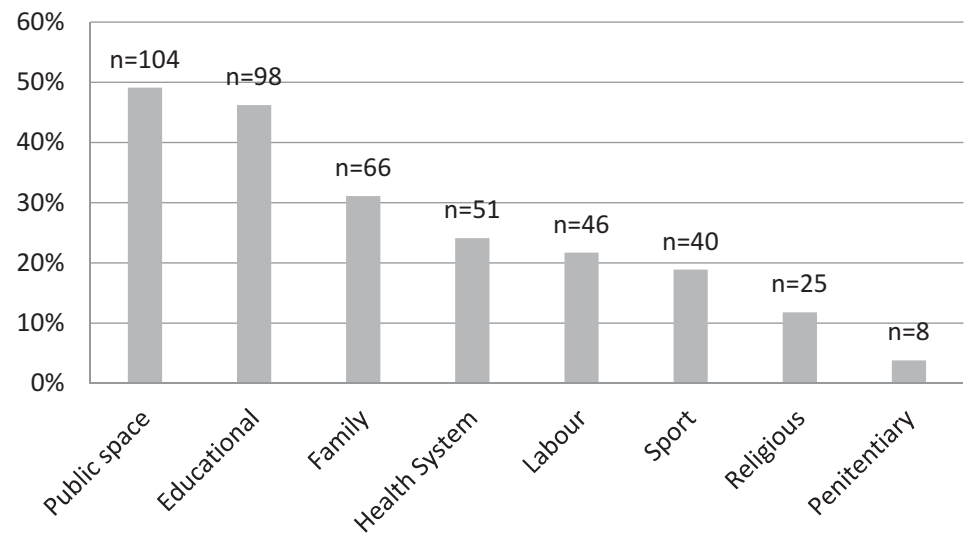

Figure 2. Percentage of harassment by contexts. 


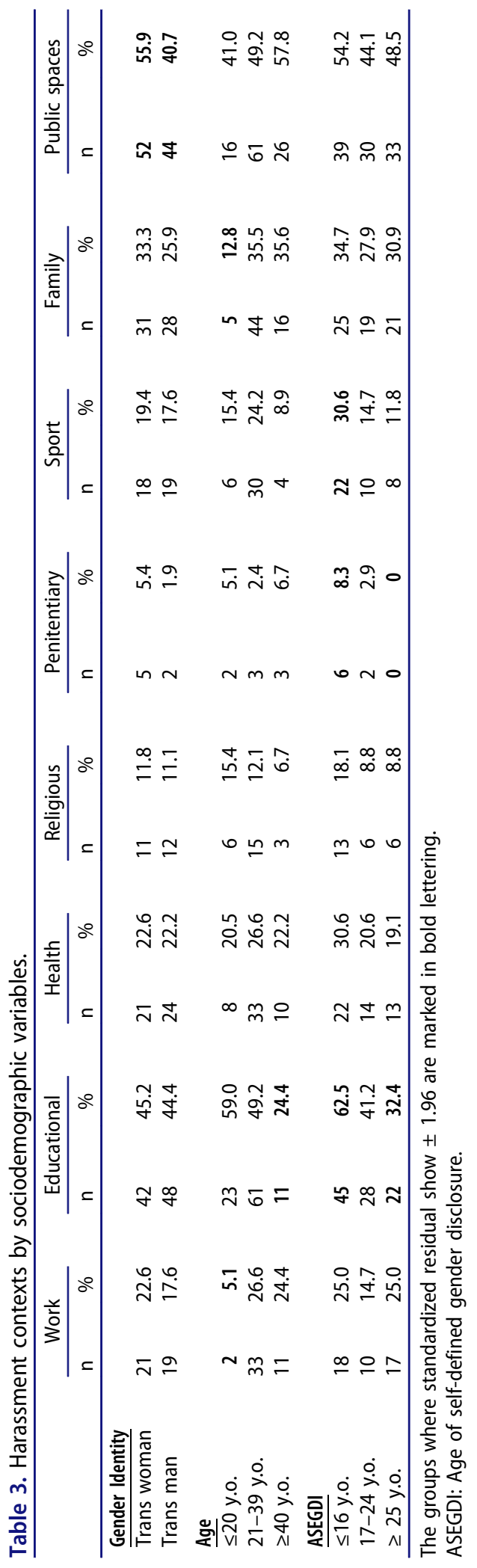


and corrected standardized residuals indicated that more trans women suffered harassment (55.9\%) than trans men (40.7\%). Analysis also showed differences by age in work $\left(\chi_{(2)}^{2}=8.132 ; p<0.05 ; V=0.198\right)$, family $\left(\chi_{(2)}^{2}=7.588 ; p<0.05 ; V=0.191\right)$, and educational $\left(\chi_{(2)}^{2}=11.573\right.$; $p<0.05 ; V=0.236)$ contexts. The study of corrected standardized residuals revealed that the younger group of participants ( $\leq 20$ years old) experienced a lower percentage of harassment in work $(5.1 \%)$ and family (12.8\%) contexts compared to the other groups (21-39 years old and $\geq 40$ years old). In contrast, the older group ( $\geq 40$ years old) suffered a lower percentage of harassment in educational context $(24.4 \%)$ than the younger participants.

Furthermore, significant differences were observed in sport $\left(\chi_{(2)}^{2}=9.282\right.$; $p<0.05 ; V=0.211)$ and educational $\left(\chi_{(2)}^{2}=13.633 ; p<0.05 ; V=0.256\right)$ contexts related to the ASEGDI. Corrected standardized residuals suggested that trans persons who disclosed their identities at an early age ( $\leq 16$ years old) suffered more harassment in sport (30.6\%) and educative (62.5\%) contexts than the rest of the participants who disclosed their identities at a later age. Chi-square analysis also displayed significant differences in penitentiary contexts $\left(\chi_{(2)}^{2}=6.791 ; p<0.05 ; V=0.181\right)$ according to the ASEGDI of participants. Nevertheless, the existence of some cells with fewer than five subjects (see Table 3) could cause overestimation of statistical significance.

\section{Risk profile of harassment}

Binomial logistic regression analysis was employed to determine the probabilities of suffering harassment according to sociodemographic profile and the types and contexts of harassment. The risk profile of harassment comes from the analysis of prediction model indicated in Table 4, once the significant differences were identified in women (see Table 1). It revealed that trans women were more likely to suffer physical harassment $(\mathrm{OR}=2.15)$ than trans men. Moreover, the likelihood to suffer different types of harassment in different contexts decreased each year that a trans person delayed the disclosure of his or her gender identity. Particularly, gestural harassment toward trans people diminished by $4 \%$, and material damage diminished by $8 \%$. The risk of harassment was also reduced by $6 \%$ in educational contexts and $15 \%$ in penitentiary settings, as well as $6 \%$ in sport contexts. Chronological age emerged as variable to predict harassment in work contexts since the risk of harassment increased 1.07 times as trans people got older.

\section{Discussion}

Data reveal that harassment is a serious problem for trans people in Spain since $59.9 \%$ of the sample are victims of harassment. This percentage is 
Table 4. Prediction model of harassment experience $(n=195)$.

\begin{tabular}{|c|c|c|c|c|c|}
\hline & $B(S E)$ & Wald & OR & $95 \% \mathrm{Cl}$ & $p$ \\
\hline \multicolumn{6}{|l|}{ Physical Harassment } \\
\hline Gender $^{(1)}$ & $0.77(0.35)$ & 4.71 & 2.15 & $1.07-4.29$ & 0.03 \\
\hline Age (years old) & $0.02(0.02)$ & 0.77 & 1.02 & $0.98-1.05$ & 0.38 \\
\hline Age of Identity Disclosure & $-0.08(0.02)$ & 11.10 & 0.92 & $0.88-0.97$ & $<0.01$ \\
\hline \multicolumn{6}{|l|}{ Gestural Harassment } \\
\hline Gender ${ }^{(1)}$ & $0.47(0.31)$ & 2.41 & 1.60 & $0.88-2.92$ & 0.12 \\
\hline Age (years old) & $0.03(0.02)$ & 2.16 & 1.03 & $0.99-1.06$ & 0.14 \\
\hline Age of Identity Disclosure & $-0.04(0.02)$ & 4.90 & 0.96 & $0.92-0.99$ & 0.03 \\
\hline \multicolumn{6}{|c|}{ Harassment with material damage } \\
\hline Gender $^{(1)}$ & $0.36(0.39)$ & 0.83 & 1.43 & $0.66-3.07$ & 0.36 \\
\hline Age (years old) & $0.02(0.02)$ & 0.55 & 1.01 & $0.97-1.06$ & 0.46 \\
\hline Age of Identity Disclosure & $-0.08(0.03)$ & 8.61 & 0.92 & $0.87-0.97$ & $<0.01$ \\
\hline \multicolumn{6}{|l|}{ Work Context } \\
\hline Gender ${ }^{(1)}$ & $0.01(0.39)$ & 0.00 & 1.01 & $0.47-2.15$ & 0.99 \\
\hline Age (years old) & $0.07(0.02)$ & 10.53 & 1.07 & $1.03-1.11$ & $<0.01$ \\
\hline Age of Identity Disclosure & $-0.04(0.02)$ & 3.54 & 0.96 & $0.92-1.00$ & 0.06 \\
\hline \multicolumn{6}{|l|}{ Educational Context } \\
\hline Gender $^{(1)}$ & $0.22(0.32)$ & 0.49 & 1.25 & $0.67-2.33$ & 0.49 \\
\hline Age (years old) & $-0.02(0.02)$ & 1.74 & 0.80 & $0.94-1.01$ & 0.19 \\
\hline Age of Identity Disclosure & $-0.06(0.02)$ & 7.31 & 0.94 & $0.90-0.98$ & $<0.01$ \\
\hline \multicolumn{6}{|l|}{ Penitentiary Context } \\
\hline Gender $r^{(1)}$ & $0.94(0.88)$ & 1.12 & 2.55 & $0.45-14.40$ & 0.29 \\
\hline Age (years old) & $0.06(0.04)$ & 2.51 & 1.06 & $0.99-1.13$ & 0.11 \\
\hline Age of Identity Disclosure & $-0.16(0.07)$ & 5.52 & 0.85 & $0.75-0.97$ & 0.02 \\
\hline \multicolumn{6}{|l|}{ Sports Context } \\
\hline Gender $^{(1)}$ & $0.27(0.39)$ & 0.48 & 1.31 & $0.61-2.78$ & 0.49 \\
\hline Age (years old) & $-0.02(0.02)$ & 0.47 & 0.98 & $0.94-1.03$ & 0.49 \\
\hline Age of Identity Disclosure & $-0.07(0.03)$ & 5.15 & 0.94 & $0.89-0.99$ & 0.02 \\
\hline
\end{tabular}

Trans women. $\mathrm{OR}=$ odds ratio. $\mathrm{Cl}=$ confidence interval.

Physical Harassment: $R^{2}=0.09$ (Hosmer and Lemeshow), 0.09 (Cox \& Snell), 0.13 (Nagelkerke). -2Log = 204.97. Model $X_{(3)}^{2}=19.14, p<0.001$.

Gestural Harassment: $R^{2}=0.03$ (Hosmer and Lemeshow), 0.04 (Cox \& Snell), 0.05 (Nagelkerke). -2Log = 260.31. Model $X_{(3)}^{2}=8.53, p<0.05$.

Harassment with material damage: $\mathrm{R}^{2}=0.06$ (Hosmer and Lemeshow), 0.06 (Cox \& Snell), 0.09 (Nagelkerke). $-2 \log =174.76$. Model $X_{(3)}^{2}=11.77, p<0.01$.

Work Context: $R^{2}=0.06$ (Hosmer and Lemeshow0.06 (Cox \& Snell), 0.09 (Nagelkerke). -2 Log = 186.02. Model $X^{2}(3)=11.87, p<0.01$.

Educational Context: $R^{2}=0.08$ (Hosmer and Lemeshow), 0.10 (Cox \& Snell), 0.14 (Nagelkerke).-2Log = 245.54. Model $X_{(3)}^{2}=21.56, p<0.001$.

Penitentiary Context: $R^{2}=0.21$ (Hosmer and Lemeshow); 0.05 (Cox \& Snell), 0.20 (Nagelkerke). -2 Log = 49.67. Model $X_{(3)}^{2}=10.65, p<0.05$.

Sports Context: $R^{2}=0.06$ (Hosmer and Lemeshow); 0.05 (Cox \& Snell), 0.09 (Nagelkerke). -2Log = 177.97. Model $X_{(3)}^{2}=11.50, p<0.01$.

substantially higher than total hate crimes committed for sexuality/gender identity (39.9\%) and racist/xenophobic (37\%) reasons in Spain. And it is far above the $15.5 \%$ of hate crimes committed toward other vulnerable persons and groups such as disabled people (Ministerio del Interior, 2015). Compared to other countries, this behavior is more prevalent in Spain than in Europe as a whole, which registers an average $43 \%$ of harassment (FRA (European Union Agency for the Fundamental Rights), 2014). It is also more prevalent than $58 \%$ of violence or crime against trans people in the United 
States (Xavier \& Simmons, 2000) and similar to $59.5 \%$ of violence or harassment experienced by trans persons in the same country (Lombardi et al., 2002). However, it is the frequency that is so alarming since $12.6 \%$ of trans persons suffer harassment on a daily basis. It is not possible to compare these percentages to the harassment experienced specifically by the cisgender population in Spain due to a lack of studies on this issue. Nevertheless, it is assumed that more trans people suffer harassment than cisgender people do as reported in other studies from the United States (Factor \& Rothblum, 2007).

The results also indicate that the important transphobic environment existing in Spain spreads through different primary and secondary socialization contexts. However, not all the contexts are affected in the same way. This study finds a different prevalence of harassment depending on the contexts where the social interactions with trans persons take place. Particularly, the highest percentage of harassment experienced by trans people in Spain is found in public areas with $49.1 \%$. Nevertheless, this is lower than the $53 \%$ and $55.5 \%$ of harassment reported by two North American studies of the same context (Grant et al., 2011; Lombardi et al., 2002). The educational environment also registers a high percentage of harassment, $46.2 \%$, which is much more than the $25 \%$ reported for primary, secondary, and higher education as a whole in Spain (Oñate \& Piñuel, 2007). Although harassment drops to $31.1 \%$ within the family setting, these situations are probably even harder to determine considering the protective function trans persons assign their families regarding harassment (Simons, Schrager, Clark, Belzer, \& Olson, 2013). However, this percentage is lower than the $66 \%$ in the United States, particularly in the city of Chicago (Kenagy \& Bostwick, 2005). Results also indicate a $24.1 \%$ of harassment within the health system, a percentage slightly different than the $28 \%$ identified in the United States (Grant et al., 2011). Participants in our study report $18.8 \%$ of harassment in sports, $11.8 \%$ in religious, and $3.8 \%$ in penitentiary contexts. These percentages are lower than the 25\%,29\%, and 14\% reported, respectively, in the United States (Minter \& Daley, 2003; Pew Research Center, 2013; Symons et al., 2010).

Regarding types of harassment, 59\% of trans people suffer verbal harassment, which represents the highest percentage among the participants in this study. It is worth noting that this result is consistent with data from other studies since verbal harassment is the most common type of harassment within the different contexts (educational, health, work, and family) (Grant et al., 2011; Greytak et al., 2009; Grossman \& D’Augelli, 2007; Lombardi et al., 2002; Reback et al., 2001). The $28 \%$ of physical harassment reported in this study falls between the $3 \%$ and $66 \%$ of harassment found in North American and Australian studies (Grant et al., 2011; Kenagy \& Bostwick, 2005; Symons et al., 2010). 
Variability analysis by sociodemographic variables of interest indicates that harassment is more prevalent in trans women than men, as suggested by other studies (Cano Oncala et al., 2004; Factor \& Rothblum, 2007). This result is also supported by binomial logistic regression since trans women are more likely to be harassed than men. Moreover, women are specifically more prevalent to be verbally and physically harassed than men, and also in public spaces or areas. On the contrary, age does not affect overall harassment and the frequency harassment, results which are similar to other studies (Cano Oncala et al., 2004; Lombardi et al., 2002). Neither is the type of harassment affected by age. However, younger participants ( $\leq 20$ years old) claim to suffer less harassment within work and family contexts than older trans people. This is probably due to the current tendency of younger people to enter the workforce later and also because the younger generations of trans persons may receive more support from their families than the older ones, as previously observed (PFLAG Transgender Network, 2007). It is worth highlighting that older participants ( $\geq 40$ years old) experience a lower percentage of harassment than younger ones within educational context. A possible explanation to this is that the ASEGDI is decreasing, meaning that older trans people probably disclosed their gender identities after finishing compulsory schooling (Gobierno de Canarias, 2013; Reguero, 2014). This makes protecting trans persons at a younger age even more important for two reasons. First, older trans persons experience less harassment in educational settings, and, second, those who disclose their gender identity at a younger age are more likely to suffer different types of harassment than those who disclose their gender identity at an older age.

In summary, the results of this study indicate that the inclusion of trans people into the Spanish society is an uncompleted task. Spain has a higher frequency of harassment and prevalence than other European countries and the United States and is probably higher than cisgender harassment. Verbal is the highest type of harassment experienced by trans people in Spain, as in other countries. Those who disclose their gender identities at a younger age experience higher percentages and frequency of harassment than older trans. The findings also indicate the presence of transphobic attitudes in Spanish society. Harassment is especially suffered by trans youngsters and women, who are also more likely to suffer physical harassment than trans men. Finally, harassment is still present in all social contexts examined in this study, and it is increasing within educational contexts.

\section{Limitations and implications}

Some potential weaknesses need to be considered in this study to accurately interpret the results. First, it was not possible to establish a representative sample due to the inexistence of a register or reliable estimation of the 
number of trans people who reside in Spain. Furthermore, because of the procedure followed to recruit participants, some marginalized trans persons with presumably different profiles of harassment may have been disregarded in the sample. However, this limitation is a common factor in most studies concerning trans people (FRA (European Union Agency for the Fundamental Rights), 2014; Grant et al., 2011; Grossman \& D’Augelli, 2007; Lombardi et al., 2002), and a more comprehensive sample would have probably increased the figures of the types of harassment reflected in this study. Second, the measurement of harassment was based on the perception of participants gathered in the survey instead of an objective measure based on the researchers' observations. Nevertheless, in the case of trans participants, the limitation is not an overrepresentation as often happens in other pattern studies. On the contrary, a risk of data underrepresentation exists with this population since trans people are more likely to perceive harassment as normal in some situations (Browne, Bakshi, \& Lim, 2011). Third, comparisons to some studies framing the discussion of results need to be cautiously considered. It must be taken into account that crime and harassment, though related, are not exchangeable realities. Therefore, specific figures of crime rate would illustrate consequences that some forms of harassment may have. Likewise, as long as our study is specifically focused on harassment, it must be considered more restricted than others also including violence and crime rates (e.g., Lombardi et al., 2002; Xavier \& Simmons, 2000). Moreover, our informants were asked whether they had ever experienced harassment and not whether they had experienced harassment for a certain period of time (e.g., 5 years, last year, last month), as is the case in other studies (e.g., FRA (European Union Agency for the Fundamental Rights), 2014; Greytak et al., 2009; Pew Research Center, 2013).

Despite these limitations, this study offers useful insights about the patterns of harassment experienced by trans people and the risk profile of harassment in Spain. This is one of the first studies to empirically address the issue of harassment in trans people living in Spain and the first one, nationally and internationally, to examine harassment according to the ASEGDI. Moreover, it analyzes the types and contexts of harassment according to sociodemographic variables of interest. Future research needs to provide in-depth understanding on how harassment actually affects trans people's lives or how they dealt with it and its consequences. Therefore, further qualitative studies that focus on the social and personal circumstances and consequences of harassment are necessary. The results of this study also urge development of intervention programs at individual, community, social, and intersectional levels, as it has been suggested for sexual minorities elsewhere (Hatzenbuehler, 2009). Harassment in public spaces, educational, and family contexts require special attention through a combined prevention strategy among local, regional, and national Spanish 
institutions. As Álvarez (2015) recently proposed, beyond medical attention and legal issues, integral trans policies become urgent in order to prevent discrimination and harassment, as well as to promote positive social attitudes and values to facilitate the inclusion of trans people in the Spanish society. Community and school interventions with families, students, teachers, and teacher educators emerge as paramount to prevent harassment among young trans people. Finally, the findings compel us to develop and debate strategies among politicians, social workers, police departments, justice staff, and Spanish social agents to promote social justice for trans people. This study aims to contribute to such ends since the results confirm that transphobic attitude change is a priority to prevent harassment of trans persons.

\section{Acknowledgments}

The authors would like to thank the participants, associations, and persons who collaborated in the field work of the research project that provides data for this article. Likewise, the authors would also thank the anonymous reviewers for contributing to the improvement of this work.

\section{Funding}

This work was supported by the Ministerio de Ciencia e Innovación of Spain under Grant number DEP2011-28190.

\section{References}

Álvarez, A. (2015, September 15). Hacia una ley integral de transexualidad [Towards a comprehensive transexuality law]. Diagonal Periódico. Retrieved from https://goo.gl/ $2 \mathrm{~g} 3 \mathrm{gzN}$

Browne, K., Bakshi, L., \& Lim, J. (2011). "It's something you just to ignore": Understanding lesbian, gay, bisexual and trans safety beyond hate crime paradigms. Journal of Social Policy, 40, 739-756. doi:10.1017/S0047279411000250

Cano Oncala, G., Bergero, T., Esteva, I., Giraldo, F., Gómez, M., \& Gorneman, I. (2004). La construcción de la identidad de género en pacientes transexuales [The gender identity construction in transexual patients]. Revista De La Asociación Española de Neuropsiquiatría, 24(89), 21-30.

Doan, P. (2010). The tyranny of gendered spaces: Reflections from beyond the gender dichotomy. Gender, Place \& Culture, 17, 635-654. doi:10.1080/0966369X.2010.503121

Factor, R. J., \& Rothblum, E. D. (2007). A study of transgender adults and their nontransgender siblings on demographic characteristics, social support, and experience of violence. Journal of LGBT Health Research, 3(3), 11-30. doi:10.1080/15574090802092879

FRA (European Union Agency for the Fundamental Rights). (2014) European Union LGTB survey. Retrieved from http://fra.europa.eu/sites/default/files/fra-eu-lgbt-survey-mainresults_tk3113640enc_1.pdf 
Gobierno de Canarias. (2013). Atención a niños y niñas con disforia de género y adolescentes transexuales en los centros escolares. Recomendaciones para docentes [Attention to children with gender disphoria and transexual adolescents in schools. Recommendations for teachers]. Las Palmas de Gran Canaria y Santa Cruz de Tenerife: Consejería de Educación, Universidades y Sostenibilidad. Retrieved from http://goo.gl/CDVBZI

Grant, J. M., Mottet, L. A., Tanis, J. T., Harrison, J., Herman, J. L., \& Keisling, M. (2011). Injustice at every turn: A report of the National Transgender Discrimination Survey. Washington, DC: National Center for Transgender Equality and National Gay and Lesbian Task Force. Retrieved from http://goo.gl/dcBEi0

Greytak, E. A., Kosciw, J. G., \& Diaz, E. M. (2009). Harsh realities: The experiences of transgender youth in our nation's schools. New York, NY: Gay, Lesbian, and Straight Education Network. Retrieved from http://goo.gl/FXQXKR

Grossman, A. H., \& D'Augelli, A. R. (2007). Transgender youth and life-threatening behaviors. Suicide and Life-Threatening Behaviors, 37, 527-537. doi:10.1521/suli.2007.37.5.527

Haas, A. P., Eliason, M., Mays, V. M., Mathy, R. M., Cochran, S. D., D’Augelli, A. R., \& ... Clayton, P. J. (2010). Suicide and suicide risk in lesbian, gay, bisexual, and transgender populations: Review and recommendations. Journal of Homosexuality, 58, 10-51. doi:10.1080/00918369.2011.534038

Hatzenbuehler, M. L. (2009). How does sexual minority stigma "get under the skin"? A psychological mediation framework. Psychological Bulletin, 135, 707-730. doi:10.1037/ a0016441

Holmes, J. R., \& Holmes-Lonergan, H. A. (2004). The bully in the family: Family influences on bullying. In C. E. Sanders \& G. D. Phye (Eds.), Bullying: Implications for the classroom (pp. 111-135). San Diego, CA: Elsevier.

Juvonen, J., \& Graham, S. (2001). Peer harassment in school: The plight of the vulnerable and victimized. Retrieved from http://goo.gl/xtQT7T

Kenagy, G., \& Bostwick, W. (2005). Health and social service needs of transgender people in Chicago. International Journal of Transgenderism, 8, 57-66. doi:10.1300/J485v08n02_06

Kidd, J., \& Witten, T. (2010). Transgender and tanssexual identities: The next strange fruithate crimes, violence, and genocide against the global trans communities. Journal of Hate Studies, 6, 31-63.

Kosciw, J. G., Greytak, E. A., Bartkiewicz, M. J., Boesen, M. J., \& Palmer, N. A. (2012). The 2011 national school climate survey. The experiences of lesbian, gay, bisexual and transgender youth in our nation's schools. Gay, Lesbian \& Straight Education Network. Retrieved from http://goo.gl/5IhE7O

Ley. (2007). Reguladora de la rectificación registral de la mención relativa al sexo de las personas [Regulative Law about changing records on persons' sex]. Boletín Oficial del Estado, 65, 11251-11253.

Ley Orgánica. (2007). Para la igualdad efectiva de mujeres y hombres [Law for effective equality between men and women]. Boletín Oficial del Estado, 71, 12611-12645.

Lombardi, E. L., Wilchins, R. A., Priesing, D., \& Malouf, D. (2002). Gender violence: Transgender experiences with violence and discrimination. Journal of Homosexuality, 42 (1), 89-101. doi:10.1300/J082v42n01_05

Ministerio del Interior. (2015). Anuario estadístico del Ministerio del Interior 2014 [2014 Yearbook of Interior Ministry]. Retrieved from http://www.interior.gob.es/documents/ 642317/1204854/Anuario-Estadistico-2014_v201510.pdf/0c18a800-f7f7-405c-9155$7391633618 \mathrm{c} 8$

Minter, S., \& Daley, C. (2003). Trans realities: A legal needs assessment of San Francisco's transgender communities. San Francisco, CA: National Center for Lesbians Rights and Transgender Law Center. Retrieved from http://goo.gl/3YeFFr 
Monks, C. P., Smith, P. K., Naylor, P., Barter, C., Ireland, J. L., \& Coyne, I. (2009). Bullying in different contexts: Commonalities, differences and the role of theory. Aggression and Violent Behavior, 14, 146-156. doi:10.1016/j.avb.2009.01.004

Nagoshi, J. L., Adams, K. A., Terrell, H., Hill, E., Brzuzy, S., \& Nagoshi, C. (2008). Gender differences in correlates of homophobia and transphobia. Sex Roles, 59, 521-531. doi:10.1007/s11199-008-9458-7

Oñate, A., \& Piñuel, I. (2007). Acoso y violencia escolar en España. Informe Cisneros X. Madrid, Spain Editorial IIEEDI.

Pew Research Center. (2013). A survey of LGBT Americans. Attitudes, experiences and values in changing times. Washington, DC: Pew Research Center. Retrieved from http://goo.gl/ pJnHGZ

PFLAG (Parents, Families and Friends of Lesbians and Gays) Transgender Network. (2007). Our trans children. Retrieved from http://goo.gl/RS6Ye3

Pörhölä, M., \& Kinney, T. (2010). Comunicación y Sociedad: Vol.5. El acoso: Contextos, consecuencias y control. Barcelona, Spain Editorial UOC.

Puche, L., Moreno, E., \& Pichardo, J. I. (2013). Adolescentes transexuales en la escuela. Aproximación cualitativa y propuestas de intervención desde la perspectiva antropológica [Transgender teenagers in school. Qualitative approach and proposals for intervention from an anthropological perspective]. In O. Moreno \& L. Puche (Eds.), Transexualidad, adolescencias y educación: Miradas multidisciplinares [Transexuality, alolecences and education: Multidisciplinary looks] (pp. 189-269). Madrid, Spain: Egales.

Reback, C., Simon, P., Bemis, C., \& Gatson, B. (2001). The Los Angeles transgender health study: Community report. Retrieved from http://goo.gl/YVmY4Y

Reguero, P. (2014, October 28). Una mirada multidisciplinar a los menores transexuales [A multidisciplinary look to transexual minors]. Diagonal Periódico. Retrieved from https:// goo.gl/rNKuzr

Silvia Rivera Law Project Organization. (2007). It's war in here": A report on the treatment of transgender and intersex people in New York state men's prisons. Retrieved from http://goo. $\mathrm{gl} / \mathrm{OIiGp} 7$

Simons, L., Schrager, S. M., Clark, L. F., Belzer, M., \& Olson, J. (2013). Parental support and mental health among transgender adolescents. Journal of Adolescent Health, 53, 791-793. doi:10.1016/j.jadohealth.2013.07.019

Stotzer, R. (2009). Violence against transgender people: A review of United States data. Aggression and Violent Behavior, 14, 170-179. doi:10.1016/j.avb.2009.01.006

Symons, C., Sbaraglia, M., Hillier, L., \& Mitchell, A. (2010). The sports experiences of lesbian, gay, bisexual and transgender (LGBT) people in Victoria. Institute of Sport, Exercise and Activity Living (ISEAL) and the School of Sport and Exercise at Victoria University. Retrieved from http://goo.gl/hSuGLE

Witten, T. M., \& Eyler, A. E. (1999). Hate crimes and violence against the transgendered. Peace Review, 11, 461-468. doi:10.1080/10402659908426291

Xavier, J. M., \& Simmons, R. (2000). The Washington transgender needs of assessment survey. Retrieved from http://goo.gl/zCilQU 